\title{
How the Chinese Fiscal Decentralization Frustrate Its County Economic Development: A Literature Review
}

\author{
Xiaoqian Liu \\ School of Economics \& Management, Southwest Jiaotong University, Chengdu, China \\ Email: juliette1220@163.com
}

Received 12 April 2016; accepted 13 May 2016; published 16 May 2016

Copyright (C) 2016 by author and Scientific Research Publishing Inc.

This work is licensed under the Creative Commons Attribution International License (CC BY).

http://creativecommons.org/licenses/by/4.0/

(c) (i) Open Access

\begin{abstract}
Fiscal decentralization has been considered as one of the essential institutional forces that can improve the quality of public goods and services as well as the allocation efficiency of regional resources in developing countries. However, along with the Chinese economy's "miracle growth" under the background of fiscal decentralization, the county economic development of China has paid the price. Therefore, this research explores how the Chinese county economy has been frustrated by its own fiscal decentralization system in two ways: The transfer payments and the power allocation among the sub-national governments in China. Especially, this paper focuses on the fiscal system under the provincial level.
\end{abstract}

\section{Keywords}

Fiscal Decentralization, The Chinese Transfer System, Power Allocation, County

\section{Introduction}

The tax sharing reform started in 1994 actually was a curtain-raiser to the Chinese fiscal decentralization (FD) reform. Under this background, the fiscal interest relations between the central and sub-national level were being unceasingly divided and adjusted; the governments under provincial level were exploring and improving the decentralization system that can adapt to their own development. Undoubtedly, the FD reform plays an active role in providing efficient public goods and services as well as in rational allocation of financial resources. The tax-sharing reform also profoundly influences the direction and development path of the Chinese economy. Nowadays, the Chinese economy is in transition; the double-track economic system is the basic characteristic of 
it. For the governments under provincial level, whether this kind of local decentralization system can bring power to the county economy development or not remains as a big question, especially under the background of the "high fiscal expenditure-fast economy growing" condition following with a series of economy development problems in counties currently. Therefore, exploring the relationship between the fiscal decentralization under provincial level and county economic development becomes significant for the perfection of Chinese fiscal system.

In China, the county governments always take on a heavy burden for providing public services including the basic education, social security, medical care and so on. The increasing amount of transfers under the FD framework has filled up the enlarging financial gap to some extent; however, the increasing amount and enlarging effects are far from enough to improve the county development in both economic and social ways. After 1994, the scale of transfers continued to enlarge; the transfer amount for sub-national governments under the provincial level has taken a proportion of $41.8 \%$ in the overall amount in 2009 . From the statistics in transfers from the higher level governments to counties, the overall transfer amount is rapidly growing year by year. However, the lake of a reasonable FD system under the provincial level has caused inefficient transfers, unreasonable allocation of financial resources and administrative affairs among sub-national governments. Therefore, this research first reviews the background how typical Chinese FD frustrates its own transfer system and sub-national power asymmetry; the second part discusses the inter-relations of fiscal decentralization, transfer payments and county development; the following part explores the fiscal decentralization, transfer payments system and county development; the last part are conclusion and suggestions.

\section{Background Review: How the Tax-Sharing Reform with Typical Chinese FD Lead to Inefficient Transfers and Sub-National Power Asymmetry}

China is the largest country with unitary system in the world; its fiscal decentralization system has shown unique characteristics. Compared with the modern federal nations, these significant characteristics could be reflected in two aspects: The first one is the steady operation of the transfer system; the second one is the appropriate assignments of tax power between national and sub-national governments.

\subsection{The Inefficient Transfers and Uneven Economic Development across the Country}

Since the 90's of 20th century, China has been strongly encouraging and pushing the regional uneven development strategy. This uneven development strategy stimulated the accelerated expansion of financial resources and the rapid economic development in eastern area, while it further intensified the polarization trend of disposable financial resources among regional governments. However, the large-scale development strategies for the western region since 2000 intended to reverse this solidified regional growth pattern were been pushing. Meanwhile, the central government began to pay attention to the transfer payment system to achieve the equalization objective (Meili, 2013) [1].

On one hand, in order to ease the financial difficulties existing in the central and western regions, the central government is trying to subsidize the central and western regions with financial resources provided by the eastern regions, under the help of incremental transfers including income taxes, system subsidies, and poverty subsidies. On the other hand, the negative effect— “whip the fast and hard working” caused by the excessive demand from eastern regions has aroused much resentment among the developing regions. Depending on the paternalism "general transfers" from central government, the western governments have already reduced the financial deficit, yet the self-sufficient ability relying on jurisdictional economic gross growth has not been improved significantly. Consequently, the governments in backward western and middle areas generally have the existing problems including “soft budget constraint” disadvantages (Xiong and Yuan, 2014) [2] (Figure 1).

\subsection{The Unbalanced Allocation of Fiscal and Administrative Powers}

Firstly, regarding to the appropriate assignment of tax power, the Chinese central government only fully authorizes regional governments with the power of taxation collection and management, yet the legislative power of taxation is strictly controlled by the central government. Hence, the spirit of Chinese FD becomes the dividing of fiscal power, instead of confirming the political power and fiscal power.

Secondly, speaking of the Chinese FD and county economic development, the Chinese county economy is 


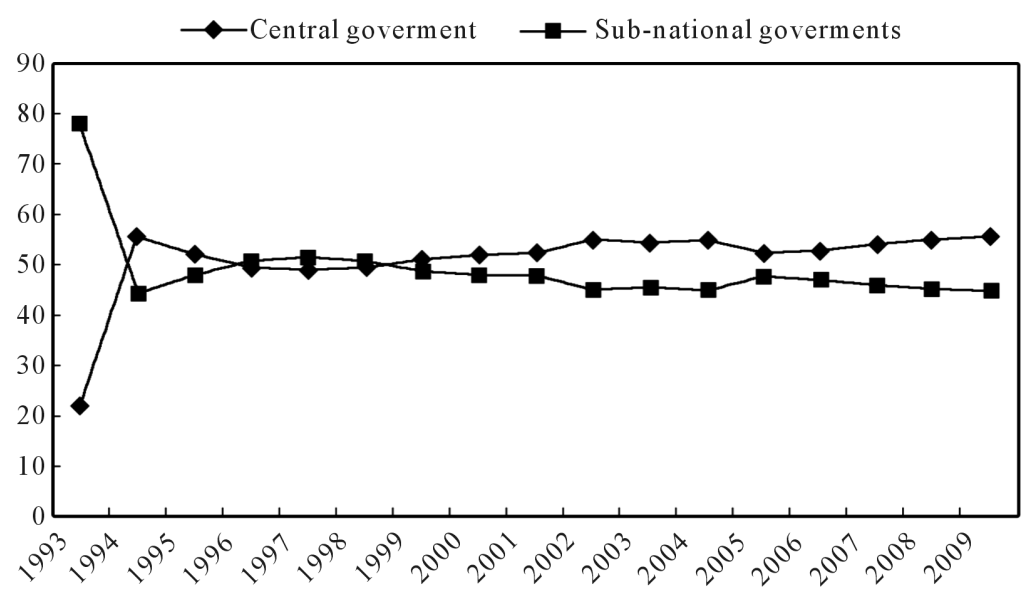

Figure 1. The proportion of regional GDP in national GDP.

influenced by the FD in two ways, up going of the power over financial affairs and lowering the governance affairs at the authority level. Based on the public goods theory and fiscal federalism, the "tax-sharing" reform began in 1994 has reassigned the public expenditure responsibility and fiscal power between central and local governments. Therefore, the county governments are forced to undertake more social and economic responsibilities. From the financial perspective, the FD brings less and less disposable income for county government, plus that the tax payment reform has reduced the source of income, the financial performance in county-level government becomes more and more serious.

The typical Chinese FD means transferring more fiscal power to lower levels but much less authorization of administrative power to sub-national governments, which shapes the current Chinese government structure as compartmentation set-up ${ }^{1}$. In addition of the "fiscal-contract" system, this governing pattern and government structure visually form a "M" framework for Chinese FD (Xian and Xu, 2009) [3]. Generally speaking, the financial issues of local governments caused by the power asymmetry between the fiscal and administrative authorization display in following aspects: the "tax-sharing" reform didn't establish a certain relationship for financial power among governments below the provincial levels; the reform however has ignored encouraging and fostering the self-financing ability of local governments under the condition of centralizing the administrative power, which makes county governments' financial issues more intensive; the predatory fiscal issues usually occur under the pressure-style FD system, along with the continuous administrative power lowering down. Eventually, this leads to steadily worse fiscal issues on county levels (Xiao, 2012) [4].

\section{The Fiscal Decentralization, Transfer Payments and County Development}

It is generally accepted that the Chinese Fiscal Decentralization Reform began with the establishment of "fiscal responsibility system" in 1980s, and then formalization of stabilized FD and transfer system was in 1994, when the tax-sharing system reform started. The "tax-sharing" reform has basically established a "central-provincialmunicipal-county" four-tier fiscal system by confirming the relationship of fiscal and administrative power between the national and sub-national governments. Specifically, the tax-sharing reform has adjusted the financial relations between the central and provincial level government; however, it fails to improve the allocation of the financial resources beyond the provincial level, which is the issue of the income division among the four levels of governments below the provincial level. After the tax-sharing reform, the Chinese financial system adopted the tax-sharing system between the central and provincial level and the "fiscal-contract" system among local governments of multi-levels below province, which has formed the so-called "double-track system" (Figure 2).

Researchers have done a series of relative research relevant to the relations between the FD system and county economy. The Chinese county economy is influenced by the FD in two ways, up going of the power over financial affairs and lowering the governance affairs at the authority level. Zhou (2007) indicated that as the final contractor of the "fiscal-contract" system, the county governments were at the bottom of the system [5]. This

${ }^{1}$ The compartmentation exactly describes the characteristic organism combination of the vertical bureaucracy of Chinese governments and subnatioanl decentralization. 


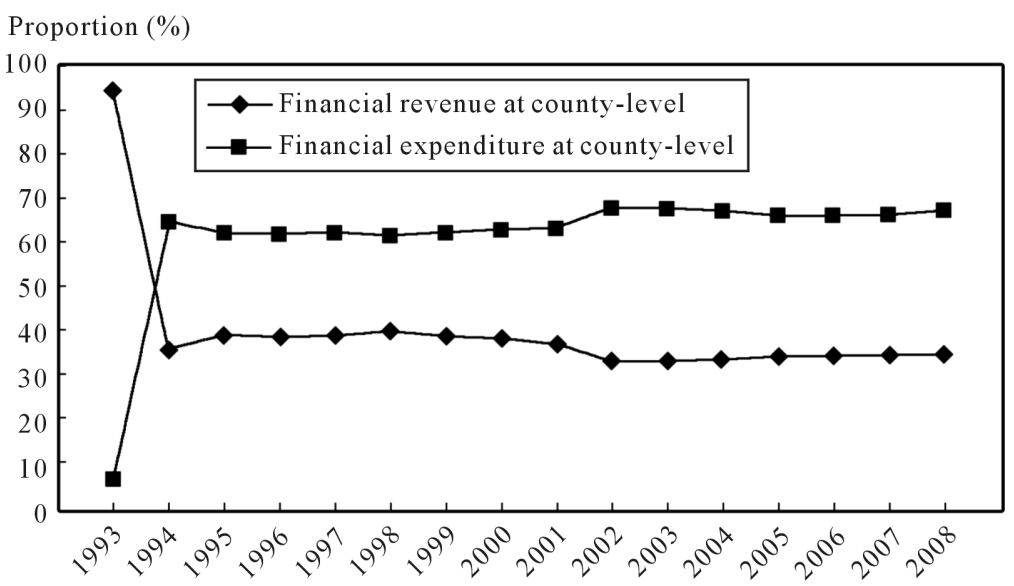

Figure 2. The proportion of financial revenue and expenditure at county-level.

means the county governments have the minimum power while bearing the maximum responsibilities, which further restricts the county economic development. Therefore, the county governments are forced to undertake more social and economic responsibilities. From the financial perspective, the FD brings about less and less disposable income for county governments, plus the tax payment reform has reduced the source of income, the financial performance of the county-level government becomes more and more serious.

Although the tax-sharing reform reduces the proportion of extra-budget revenue, the extra-budget revenue is growing slowly compared with the central revenue. However, in order to release the financial pressure in poor basic level governments, a great majority of local governments in China are forced to bypass the budget law and process indirect financing, by establishing investment companies owned by local governments. Meanwhile, the governments also encourage local resources flowing into the extra-budgetary fiscal field where the central government has difficulties to supervise or control. Therefore, the rapid expansion of government debt associated with growing extra-budgetary funds eventually lead to corruption and unstable macro-economic environment (Qi, 2005) [6]. Because of these driving forces, speeding up the progress of establishing a transfer payment system aiming at intergovernmental fiscal equalization becomes a key point to solve the financial difficulties that the sub-national governments currently have (Figure 3, Figure 4).

As the intergovernmental fiscal equalization emphasizes more on the fairness of disposable financial resources, the key of the assessment here is to strictly define the responsibility area of the public expenditure for local governments, and the relationships between its responsibilities and financial power as well. Alfred (2013) points out that the core content of the transfer system in China should rely on making up the balance of public expenditure, instead of carrying out the "fiscal equalitarianism" policy [7]. Although the transfer system in China began with the tax-sharing system reform and experienced several structural adjustments and modifications, the current transfers from central government to local ones in China have formed a dual transfer payment system basically, which focuses on the financial transfers primarily and regards the special transfers only as supplements.

In order to remain the balance of vested interests among local governments, the central government adopted the "tax return" policy based on the value added tax and consumption tax (VAT and CT) that turned over to central government. In addition, the financial transfers have also covered the "general transfers" funds aiming at fiscal equalization, which were represented by function as system subsidy, settlement subsidy, and incremental transfers. These elements together have constructed the central content of the current Chinese transfer payment system.

As the various differences in natural resources and the development conditions existing across areas have caused growing income disparities and investment cost variances, the essential productive factors and human capital flow within different jurisdictions. Correspondingly, the apparent regional disparities are shown in available fiscal and taxation resources. This migration caused by regional disparities of available financial resources unavoidably fails to reflect the differences of the actual factor cost and actual conditions of relative resources, which eventually leads to an "overall efficiency loss." A country with vast territory like China, its available resources for economic development are various among different areas, the huge regional economic 


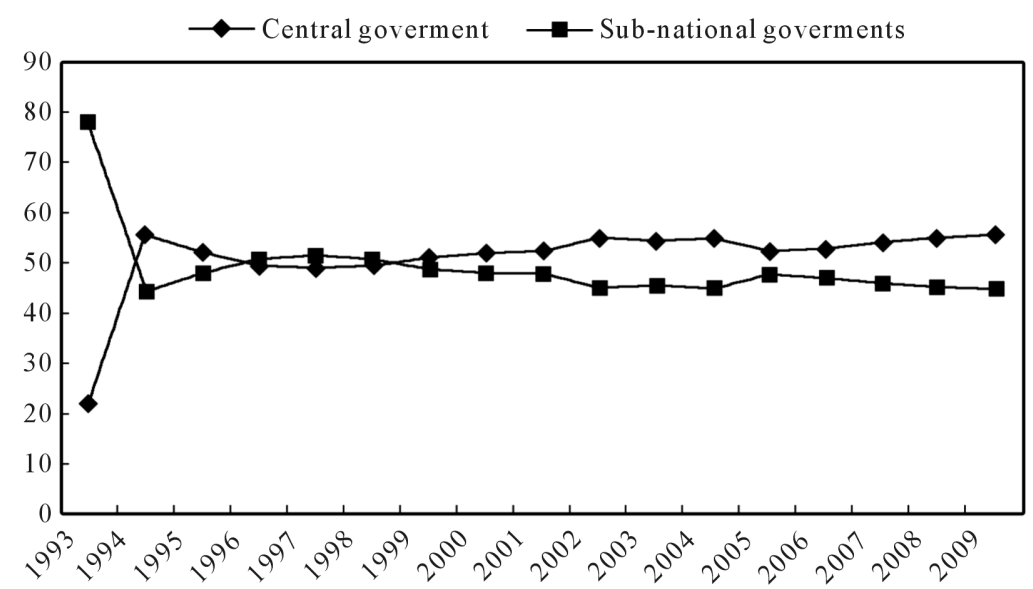

Figure 3. The percentage of central and sub-national financial revenue after tax-sharing reform.

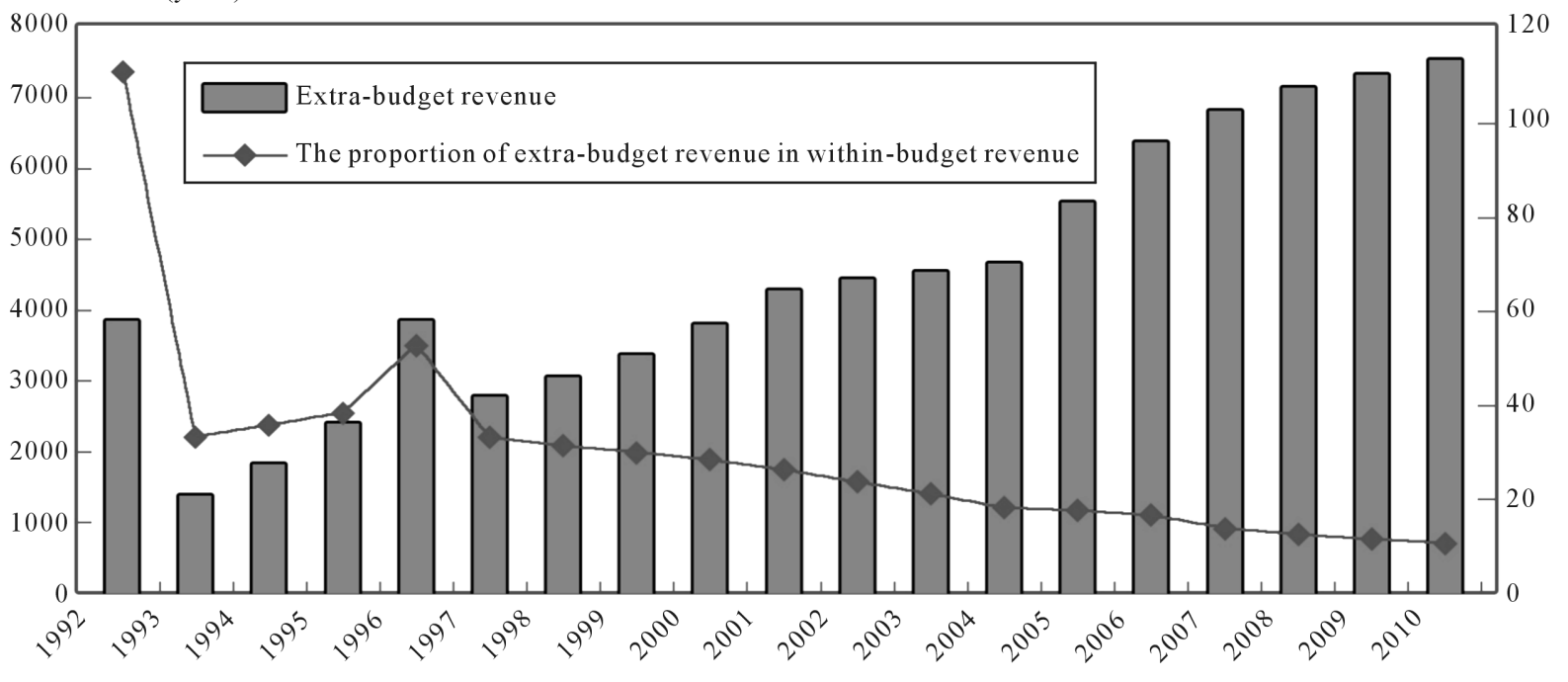

Figure 4. Changes of extra-budget revenue after tax-sharing reform.

development disparity also exist between counties, the ability of obtaining financial resources thus differ from counties to counties. As discussed above, the Chinese FD has created huge differences in economic development conditions among counties across the country. From the perspective of the whole nation, the inter-governmental transfer system that the central government attempted to establish is an effective way to correct the overall efficiency loss created by regional differences. To be specifically, the transfers can be seen as financial assistance for the under-developed areas whose resources have been forced to transfer to developed areas. Therefore, the under-developed counties that are lack of financial resources under the current system can acquire corresponding financial subsidies with the help of transfers. The transfers from provinces and cities to lower levels include general transfer payments and special transfer payments. The general transfers include revenue of tax return, systematic subsidy, and balanced transfer subsidy. The specific transfers include provincial counterpart funding from central level to county level, project funding from provincial level to county level and incentive transfers. The amount of transfers from provinces to lower levels is differ from area to area: the official transfers many provinces announced have already included the transfers of central government; few provinces set up the general transfer subsidy system based on formulas; most provinces only assign the funds from central government to cities and counties and provide the counterpart funds that the central government requests passively.

The inter-governmental transfer system is commonly used by countries with tax-sharing fiscal system. This transfer system is an essential system aimed to solve the issue of unbalanced fiscal power among sub-national 
governments from vertical and horizontal levels. Since the tax-sharing reform started in 1994, China is continuously improving its fiscal transfer payments system. However, under the Chinese fiscal decentralization system, the transfers fail to benefit the economic development of Chinese counties as the contradiction between the system and the objective demands. Furthermore, the contradiction situation mainly demonstrates in the following three ways: the slow growing speed of the proportion of transfers in factor-transfer payments, the real transfer objective is unclear as a whole, the regional regulatory function is weak; a concrete system to divide the administrative powers hasn't been set up; a unified and standard spending system hasn’t been set up completely (Figure 5, Figure 6).

Xiao (2008) indicated that the sub-national transfers included two major types, which are security transfers and incentive transfers [8]. The security transfers calculate the revenue and expenditure gap by using factor method, which aims at balancing the city and county financial powers and solving the "eating and operation" difficulties. However, the incentive transfers aims at encouraging the counties and cities to enlarge the financial revenue scale, strength the expenditure management system and control the population amount that financial support through the reward and punishment system. As the general transfers with obvious balance effects only take a relatively small proportion in the transfer system, the overall effects of balancing the inter-governmental financial powers is not obvious.

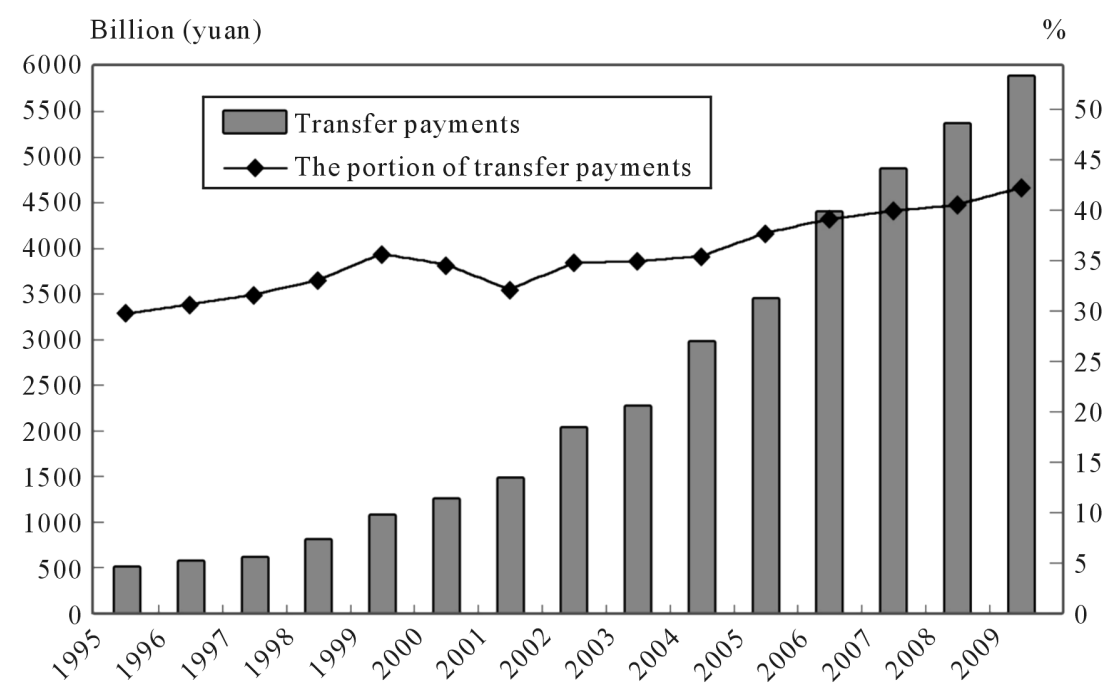

Figure 5. The transfer amount and percentage for western area.

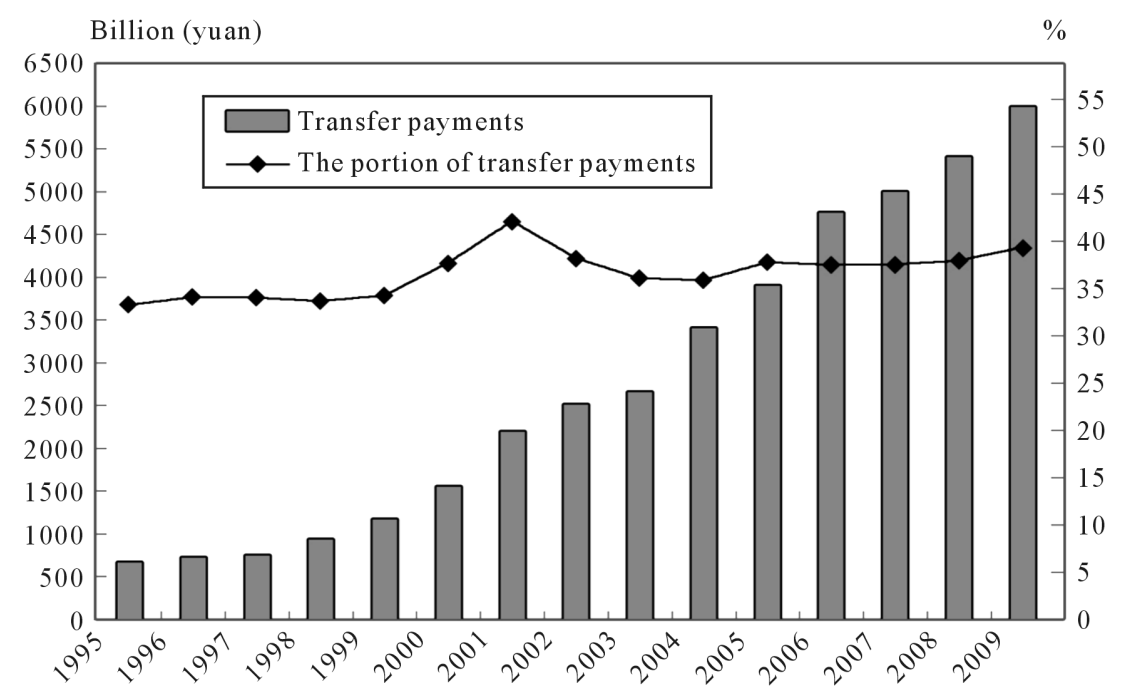

Figure 6. The transfer amount and percentage for middle area. 


\section{The Power Allocation beyond Provincial Levels and County Economic Development}

As discussed above, research concerning the Chinese FD is relative late compared with the developed countries. The FD reform started in late 1980s was mainly embodied with the confirmation of the fiscal systematic relations between the central and provincial levels; however, the fiscal relations among local governments beyond the provincial levels had never been sorted out since. At the early stage of the FD reform, the central government barely interfered the local inter-governmental fiscal relations directly, each province could decide the fiscal relations between the province and a-level cities as well as the relations between the province and counties. After the tax sharing system in 1994, the distribution system of fiscal relations between the central and local governments has been basically established Based on this tax-sharing reform, local governments adjusted their own fiscal system while setting up the matching transfer system. Generally speaking, the tax sharing reform was meant to overcome the defects brought by fiscal contract system and to strength the financial capabilities for central government shortly. Therefore, the current tax sharing system only solved the fiscal power distribution issue between central and provincial levels, but ignored the contradiction in financial power distribution among sub-national governments.

The revenue distribution beyond provincial levels among local governments are well defined, the implementation measures are differ from regions to regions. The sub-national governments mainly adopt two methods, tax sharing and pro rata sharing. Most provinces put the tax revenue from major industries under provincial levels. In ways of dividing method, some divide the revenue by proportion, some divide the revenue by enterprise category, and some divide the revenue by the former two types together.

Compared with the methods of revenue division, the division of administrative authority is only a vague shape; the spending responsibility is far less clear. The laws in China have not divided the administrative authority among governments at all levels clearly. Normally, the upper governments decide the spending responsibilities for lower governments in sequence. In fact, besides the few authorities like diplomacy and national defenses are only belonged to the central government, the authorities each sub-national government holding don't have many differences. Furthermore, the spending responsibilities are related to each government's interest, the spending system is thus instability. Liu (2005) indicated that many provincial governments' already undertook important responsibilities such as economy and culture development, political stability and so on, means that they did not only solve the social management issues, but also solved the equalization issue of public services and so on [9]. As huge differences in economic and natural conditions exist within every province, the equalization tasks are tremendous. As a result of this, improving the provincial ability of macro adjusting is necessary. Specifically, there are two ways to reduce the macro control function of city levels: One is the rulemaking powers on economy, the other one is distribution of financial powers. Speaking of the county levels, the county governments are the most basic level government, the range of social management affairs they undertaking is broad, and the responsibilities are heavy. From the view of the Chinese urbanization progress, enhancing their economic control ability will be able to speed up the urbanization progress and serve the national strategy of economic and social development. Meanwhile, the county governments are also the cornerstone of state political power and economic construction; the financial conditions of the county governments are directly related to the general national interests. Moreover, the town and village level governments of China have lost their original function of macroeconomic administration; especially the governments in poor areas barely have any financial power. Take the Feixi County in Hefei City as an example, this county is a typical agricultural production area that doesn't have any independent income, the governmental operation funds rely fully on superior allocate funds. This kind of village and town government can’t be seen as one-level government (Jiakang, 2005) [10].

In brief, the basic principle of administration authority division among governments is as following: when the public goods are more divisible and the interests' concentration degree is higher, the public goods should be provided by sub-national governments, like keeping public order; as the transaction costs of cross-area teamwork are very high, consequently, the public goods cross-area are always provided by superior governments. The spending responsibilities of social security such as pension benefits, unemployment issues and medical care should be definitely assigned to the provincial levels (Xiao, 2008) [8].

\section{Conclusion}

From the research of the relations between the fiscal decentralization reform and Chinese county economic de- 
velopment, it can be seen that the Chinese county development is frustrated by the decentralization system under provinces in two major ways. One is the inefficient transfers within the current tax-sharing system; the other is sub-national power asymmetry among sub-national governments. In order to improve the quality county economic development, the suggestions are as follows: Firstly, it is necessary to build a reasonable and efficient system with reasonable power allocation, trying to achieve the goal of "one-level administrative power, one-level fiscal power, and one-level tax power”. Secondly, it is necessary to improve the transfer system within provinces, integrate the current transfer system, enlarge the proportion of general transfers concerning with economy development, and introduce the incentive distribution mechanism in specific transfers. Thirdly, as the regional disparities exist in the Chinese fiscal system and abilities to provide public services, the central government should consider fiscal equalization as a major issue in the process of adjusting transfer system.

\section{References}

[1] Meili, N. (2013) Fiscal Decentralization in China Revisited. Australian Journal of Public Administration, 72, 251-263. http://dx.doi.org/10.1111/1467-8500.12026

[2] Cao, S.X., Lv, Y., Zheng, H.R. and Wang, X. (2014) Challenges Facing China's Unbalanced Urbanization Strategy. Land Use Policy, 39, 412-415. http://dx.doi.org/10.1016/j.landusepol.2013.12.004

[3] Wang, X.B. and Xu, X.X. (2009) On the Development Behavior of Local Officials in China: An Analysis based on Political Incentive and Federalism. Nankai Economics Studies, 2, 58-79.

[4] Liu, X.Y. (2012) Tax Share System, Transfer and Local Government Fiscal Effort. South China Journal of Economics, 5, 38-52.

[5] Zhou, L.A. (2007) Governing China’s Local Officials: An Analysis of Promotion Tournament Model. Economic Research Journal, 7, 36-50.

[6] Zhan, Q.C. (2005) Inter-Government Transfer Payment and Variation in Regional Financial Gap. Journal of Zhongnan University of Economics and Law, 6, 111-117.

[7] Alfred, M. and Wen, W. (2013) Determinants of Expenditure Decentralization: Evidence from China. World Development, 46, 176-184. http://dx.doi.org/10.1016/j.worlddev.2013.02.004

[8] Zhao, X.H. (2008) The Reform Compose of Fiscal System under Provinces. Shandong Social Science, 11, 67-70.

[9] Liu, J.H. (2005) the Institutional Economic Analysis of Sub-National Fiscal Reform. The Academic Journal of Northwest University, 4, 98-105.

[10] Jia, K. (2005) The Thinking of Improving the Fiscal Reform under Provincial Level. The Administrative World, 8, 33-37. 